\title{
TAXA DE MULTIPLICAC̃̃̃O E EFEITO RESIDUAL DE DIFERENTES FONTES DE CITOCININA NO CULTIVO in vitro DE Hancornia speciosa GOMES ${ }^{1}$
}

\author{
Proliferation rate and residual effect of different sources of cytokinin on \\ in vitro culture of Hancornia speciosa Gomes $^{1}$ \\ Fernanda Pereira Soares ${ }^{2}$, Renato Paiva ${ }^{3}$, Amauri Alves de Alvarenga ${ }^{3}$, \\ Fernanda Carlota Nery ${ }^{4}$, Daiane Peixoto Vargas ${ }^{3}$, Douglas Ramos Guelfi Silva ${ }^{5}$
}

\begin{abstract}
RESUMO
A mangabeira destaca-se por possuir um grande potencial como planta frutífera. Suas sementes apresentam recalcitrância, dificultando sua propagação, o que torna evidente a necessidade da obtenção de mudas por via assexuada. Neste contexto, a cultura de tecidos apresenta-se como uma alternativa a ser utilizada. Entre os fatores que afetam a morfogênese in vitro, as citocininas merecem destaque, pois influenciam na diferenciação de gemas e no crescimento das brotações. Assim sendo, avaliou-se, neste trabalho, a influência de três diferentes fontes de citocinina (6-benzilaminopurina - BAP, cinetina - CIN e thidiazuron - TDZ) na indução de brotações in vitro de mangabeira, bem como o efeito residual dessa classe de reguladores no enraizamento e na multiplicação em subcultivos sucessivos. Os resultados mostraram que, entre as citocininas testadas, a 6-benzilaminopurina foi a que induziu maior número de brotações $(1,98)$, gemas $(19,22)$ e folhas $(18,86)$ por explante, tendo promovido a formação de brotos de maior comprimento $(4,55 \mathrm{~cm})$. As brotações oriundas de meio WPM basal apresentaram maior facilidade de enraizamento. A 6-benzilaminopurina foi responsável pela maior taxa de multiplicação $(9,61)$ de brotações de mangabeira. Os subcultivos sucessivos diminuíram a capacidade de multiplicação de explantes caulinares da espécie.
\end{abstract}

Termos para indexação: Micropropagação, mangabeira, subcultivos.

\section{ABSTRACT}

The mangabeira stands out for having a strong potential for fruit production. Its seeds present recalcitrance, making its propagation difficult, which makes much clear the need to obtain seedlings through asexual methods. In this context, the tissue culture presents as an alternative to be used. Among the factors that affect in vitro morphogenesis, the cytokinins should be highlighted as it influences the differentiation of buds and shoot growth. In this context the influence of three different sources of cytokinins (6-benzylaminopurine - BAP, kinetin - CIN and thidiazuron - TDZ) was evaluated on the induction of in vitro mangabeira shoots, as well as the residual effect of this type of regulator on rooting and multiplication in successive subcultures. The results showed that among the tested cytokinins, the 6-benzylaminopurine was the one that induced a higher number of shoots (1.98), buds (19.22) and leaves (18.86) per explant, promoting the formation of shoots with higher length $(4.55 \mathrm{~cm})$. The shoots from basal WPM medium rooted easier. The 6-benzylaminopurine was responsible for the highest rate of multiplication (9.61) of mangabeira shoots. Sucessive subcultures decreased the capacity of shoot multiplication.

Index terms: Micropropagation, mangabeira, subcultures.

(Recebido em 30 de abril de 2010 e aprovado em 14 de setembro de 2010)

\section{INTRODUÇÃO}

A mangabeira, pertencente à família Apocynaceae, é uma espécie frutífera de clima tropical que vegeta espontaneamente no Nordeste do Brasil e também no Cerrado da região central do país (Soares et al., 2009). Produz frutos comestíveis, consumidos in natura e utilizados na industrialização de sucos, doces e sorvetes.

De acordo com Campbell (1996), a propagação dessa espécie por métodos tradicionais tem sido dificultada pelo fato de suas sementes serem recalcitrantes. Além disso, por ser alógama, sua propagação por via sexuada resulta em elevado grau de variabilidade de inúmeras características de importância econômica.

A propagação vegetativa por meio de estaquia, enxertia e mergulhia, para a mangabeira, também não tem logrado êxito suficiente para ser utilizada em viveiros comerciais.

Neste contexto, a micropropagação surge como uma ferramenta da biotecnologia para fixar genótipos de

${ }^{1}$ Parte da Tese de Doutorado em Fisiologia Vegetal, apresentada pelo primeiro autor à Universidade Federal de Lavras/UFLA - Lavras, MG ${ }^{2}$ Ministério da Agricultura Pecuária e Abastecimento - Unidade Técnica Regional de Agricultura, Pecuária e Abastecimento de Lavras - Campus Histórico da Universidade Federal de Lavras/UFLA - Cx. P. 163 - 37200-000 - Lavras, MG - fernanda.soares@agricultura.gov.br ${ }^{3}$ Universidade Federal de Lavras/UFLA - Departamento de Biologia/DBI - Lavras, MG

${ }^{4}$ Universidade Federal de São João Del Rei/UFSJ - Departamento de Engenharia de Biossistemas/DEPEB - São João Del Rei, MG

${ }^{5}$ Universidade Federal de Lavras/UFLA - Departamento de Ciência do Solo/DCS - Lavras, MG 
interesse e auxiliar no conhecimento da fisiologia da planta (Lima et al., 2008; Gomes et al., 2010). A utilização desse método permite uma multiplicação em larga escala e em curto espaço de tempo a partir de pequenos fragmentos de tecidos.

Entre os fatores que controlam a morfogênese in vitro, destacam-se os reguladores de crescimento, sendo as citocininas, juntamente com as auxinas, as classes mais utilizadas. Além de serem essenciais à citocinese, promovem alterações na taxa metabólica, atividade enzimática, indução e formação de órgãos, quebra de dominância apical, mobilização de nutrientes orgânicos e inorgânicos e aumento da longevidade de tecidos e órgãos (Howell et al., 2003; Oliveira et al., 2007).

Dentre as citocininas comercialmente disponíveis, a 6-benzilminopurina (BAP) é a que, em geral, tem apresentado melhores resultados in vitro na promoção da multiplicação de diversas espécies, sendo utilizada em aproximadamente $60 \%$ dos meios de cultivo, seguida da cinetina (CIN), com cerca de $23 \%$ (Grattapaglia \& Machado, 1998). De acordo com Peres (2002), o efeito diferencial dos vários tipos de citocininas, quando aplicados ao meio de cultura, pode estar relacionado ao fato de cada um deles interferir de modo particular no metabolismo hormonal endógeno.

Objetivou-se, neste trabalho, avaliar a influência de diferentes citocininas na indução de brotações in vitro de mangabeira, bem como o efeito residual dessa classe de reguladores no enraizamento e na multiplicação em subcultivos sucessivos.

\section{MATERIAL E MÉTODOS}

Os explantes, constituídos de segmentos caulinares contendo até duas gemas laterais, foram obtidos de plântulas de mangabeira germinadas in vitro em meio Wood Plant Medium (WPM), definido por Lloyd \& McCown (1980) e, após isolados, foram inoculados em tubos de ensaio $(25 \times 150 \mathrm{~mm})$ contendo $15 \mathrm{~mL}$ de meio WPM, suplementado com $30 \mathrm{~g} \mathrm{~L}^{-1} \mathrm{de}$ sacarose.

O meio foi solidificado com $0,7 \%$ de ágar, tendo seu pH ajustado para 5,8 antes da autoclavagem. Os tratamentos consistiram da adição de 6-benzilaminopurina (BAP), thidiazuron (TDZ) e cinetina (CIN), todos na concentração de $2 \mathrm{mg} \mathrm{L}^{-1}$, padronizada com base em testes preliminares. Como controle, utilizou-se o tratamento sem adição de citocinina. Após a inoculação dos explantes, procedeu-se à vedação dos tubos com tampas e filmes plásticos. Os explantes foram mantidos em sala de crescimento com fotoperíodo de 16 horas, irradiância de fótons de $50 \mu \mathrm{mol} \mathrm{m} \mathrm{m}^{-2} \mathrm{~s}^{-1}$ e temperatura de $27 \pm 2^{\circ} \mathrm{C}$. Foram avaliados o número de brotações, de gemas e de folhas por explante e o comprimento da maior brotação aos 35 dias de cultivo.

Para o enraizamento, as brotações de mangabeira provenientes de meio de cultura suplementado com $2 \mathrm{mg} \mathrm{L}^{-1}$ das diferentes fontes de citocininas (BAP, TDZ e CIN), após individualizadas e marcada sua fonte, foram inoculadas em meio WPM suplementado com $30 \mathrm{~g} \mathrm{~L}^{-1}$ de sacarose e $1 \mathrm{mg} \mathrm{L}^{-1}$ de ácido indolbutírico (AIB), permanecendo em sala de crescimento, no escuro, a $27 \pm 2^{\circ} \mathrm{C}$ de temperatura. Quinze dias depois, foram transferidas para meio WPM basal e, durante 30 dias, permaneceram em ambiente com fotoperíodo de 16 horas, irradiância de fótons de $50 \mu \mathrm{mol} \mathrm{m} \mathrm{m}^{-2}$ e temperatura de $27 \pm 2^{\circ} \mathrm{C}$. Foram avaliados o número de raízes por brotação e o comprimento da maior raiz formada.

Para ambos os experimentos, adotou-se o delineamento inteiramente casualizado, com cinco repetições de 10 explantes por tratamento. Para análise estatística foi utilizado o programa SISVAR 4.6 (Ferreira, 1999). As médias foram comparadas pelo teste de Scott \& Knott a 5\% de probabilidade de erro.

Para avaliação do efeito residual das diferentes fontes de citocininas utilizadas, as brotações de mangabeira originadas do cultivo in vitro em meio WPM basal e em meio WPM suplementado com $2 \mathrm{mg} \mathrm{L}^{-1}$ de BAP, CIN e TDZ foram subcultivadas por três vezes, em intervalos de 35 dias, inoculando-se os explantes caulinares (com duas gemas axilares) no mesmo meio de cultura anterior.

Após cada inoculação, os tubos foram vedados com tampas e filmes plásticos e mantidos em sala de crescimento a $27 \pm 2^{\circ} \mathrm{C}$ de temperautra, irradiância de fótons de $50 \mu \mathrm{mol} \mathrm{m} \mathrm{m}^{-2} \mathrm{~s}^{-1} \mathrm{e}$ fotoperíodo de 16 horas. Foram avaliados, ao final do cultivo inicial (35 dias) e em cada um dos subcultivos, a taxa de multiplicação, o número de brotações e gemas por explante e o comprimento da maior brotação formada. A taxa de multiplicação foi determinada dividindo-se o número de gemas, obtido ao final de cada período de 35 dias, pelo número inicial de gemas do explante, segundo metodologia descrita por Erig \& Schuch (2002). Foi utilizado o delineamento estatístico inteiramente casualizado, com quatro repetições de 5 explantes por tratamento. Para análise estatística, utilizouse o programa SISVAR 4.6 (Ferreira, 1999). As médias foram comparadas pelo teste de Scott-Knott a $5 \%$ de probabilidade de erro. 


\section{RESULTADOS E DISCUSSÃO}

A formação de brotações ocorreu em todos os tratamentos testados (Tabela 1), mesmo na ausência do regulador de crescimento. Entretanto, a adição de citocininas ao meio de cultura basal propiciou um incremento da proliferação de brotos.

Tabela 1 - Efeito da adição de 6-benzilaminopurina (BAP), cinetina (CIN) e thidiazuron (TDZ) $\left(2,0 \mathrm{mg} \mathrm{L}^{-1}\right)$ ao meio WPM sobre o número médio de brotações, folhas e gemas, e no comprimento da maior brotação formada em explantes caulinares de mangabeira, 35 dias após a inoculação.

\begin{tabular}{ccccc}
\hline $\begin{array}{c}\text { Fonte de } \\
\text { citocinina }\end{array}$ & $\begin{array}{c}\mathrm{N}^{\mathrm{o}} \text { de } \\
\text { Brotações }\end{array}$ & $\begin{array}{c}\text { Comprimento } \\
\text { da maior } \\
\text { brotação }(\mathrm{cm})\end{array}$ & $\begin{array}{c}\mathrm{N}^{\mathrm{o}} \mathrm{de} \\
\text { gemas }\end{array}$ & $\begin{array}{c}\mathrm{N}^{\mathrm{o}} \mathrm{de} \\
\text { folhas }\end{array}$ \\
\hline Controle & $1,58 \mathrm{~b}$ & $1,78 \mathrm{c}$ & $5,96 \mathrm{c}$ & $5,02 \mathrm{c}$ \\
BAP & $1,98 \mathrm{a}$ & $4,55 \mathrm{a}$ & $19,22 \mathrm{a}$ & $18,86 \mathrm{a}$ \\
CIN & $1,92 \mathrm{a}$ & $3,46 \mathrm{~b}$ & $10,20 \mathrm{~b}$ & $9,80 \mathrm{~b}$ \\
TDZ & $1,70 \mathrm{~b}$ & $3,13 \mathrm{~b}$ & $11,32 \mathrm{~b}$ & $10,90 \mathrm{~b}$ \\
\hline
\end{tabular}

*Em cada coluna, as médias seguidas pela mesma letra não diferem significativamente entre si, de acordo com o teste de Scott-Knott, a $5 \%$ de probabilidade de erro.

As maiores médias observadas, 1,98 e 1,92 brotações por explante, resultaram da adição ao meio nutritivo de BAP e CIN, respectivamente. Resultados semelhantes foram obtidos por Santos et al. (2005) que, trabalhando com explantes caulinares de Anana erectifolius $\mathrm{L}$. B. Smith, verificaram a formação de maior número de brotos ( 5,83 por explante) em meio de cultura suplementado com 2,0 $\mathrm{mg} \mathrm{L}^{-1}$ de BAP. Oliveira et al. (2007), em experimentos visando à indução de brotações em Annona glabra L., observaram a formação de 1,33 e 1,26 brotos por explante quando adicionaram ao meio de cultura WPM 1,0 $\mathrm{mg} \mathrm{L}^{-1}$ de BAP e CIN, respectivamente.

Das citocininas testadas, o TDZ foi a que propiciou a menor proliferação de brotos (1,7 por explante), os quais, ao longo da cultura, apresentaram-se mal formados, com caules retorcidos e folhas atípicas. Observações semelhantes foram feitas por Mantovani et al. (2001), na multiplicação de Cordia trichotoma.

Várias anormalidades morfo-fisiológicas têm sido associadas ao uso do TDZ, como hiperhidria (Gribaudo \& Fronda, 1991), morfologia anormal de folhas (Gribaudo \& Fronda, 1991; Kim et al., 1997), gemas curtas e não alongadas (Kim et al., 1997), gemas fasciadas (Huetteman \& Preece, 1993) e diminuição ou eliminação do enraizamento (Gribaudo \& Fronda, 1991).
A formação de menor número de brotos com a utilização do TDZ pode estar relacionada ao fato dessa citocinina ser mais ativa biologicamente que as demais. De acordo com Ribeiro et al. (2010), a maior atividade biológica do TDZ na multiplicação, em relação a outras fontes, se deve ao incremento da atividade da enzima fosfatase ácida, responsável pela interconversão nucleotídeo-nucleosídeo da estrutura de citocininas endógenas, tornando-as biologicamente ativas, atuando como um inibidor de crescimento se utilizado em elevadas concentrações.

Com relação ao comprimento do maior broto formado, a maior média $(4,55 \mathrm{~cm})$ foi verificada em brotações mantidas na presença de BAP no meio nutritivo. De modo semelhante, maior número de gemas e de folhas $(19,22$ e 18,86, respectivamente) foi observado em explantes caulinares inoculados em meio de cultura suplementado com BAP. Os menores valores foram encontrados em meio WPM basal.

$\mathrm{O}$ incremento do número de gemas, verificado com a suplementação do meio nutritivo com BAP, está diretamente relacionado ao maior número de brotações formadas na presença dessa citocinina, concordando com os resultados obtidos por Morales et al. (1999) que, trabalhando com macieira, também observaram intensa formação de gemas nessas condições de cultivo.

$\mathrm{Na}$ etapa de enraizamento in vitro, foi verificada a formação de raízes em todos os tratamentos testados. Observou-se, no entanto, maior capacidade de enraizamento das brotações oriundas de meio de cultura basal e com adição de TDZ em relação às que foram multiplicadas na presença das demais fontes de citocininas. A adição de CIN e BAP ao meio de cultura durante a fase de multiplicação provocou uma redução significativa no número de raízes formadas por explante (Tabela 2).

Tabela 2 - Efeito residual de 6-benzilaminopurina (BAP), cinetina (CIN) e thidiazuron (TDZ) $\left(2,0 \mathrm{mg} \mathrm{L}^{-1}\right)$ sobre o número médio de raízes e comprimento da maior raiz formada em brotações de mangabeira, 45 dias após a inoculação.

\begin{tabular}{ccc}
\hline $\begin{array}{c}\text { Fonte de } \\
\text { citocinina }\end{array}$ & $\mathrm{N}^{\mathrm{o}}$ de Raízes & $\begin{array}{c}\text { Comprimento da } \\
\text { maior raiz }(\mathrm{cm})\end{array}$ \\
\hline Controle & $1,70 \mathrm{a}$ & $0,94 \mathrm{a}$ \\
BAP & $0,75 \mathrm{~b}$ & $0,09 \mathrm{~b}$ \\
CIN & $0,35 \mathrm{~b}$ & $0,09 \mathrm{~b}$ \\
TDZ & $1,95 \mathrm{a}$ & $0,35 \mathrm{~b}$ \\
\hline
\end{tabular}

*Em cada coluna, as médias seguidas pela mesma letra não diferem significativamente entre si, de acordo com o teste de Scott-Knott, a 5\% de probabilidade de erro. 
Resultados semelhantes foram obtidos por Machado et al. (2006) que, trabalhando com a multiplicação in vitro de porta-enxerto de videira 'VR043-43', observaram que as diferentes concentrações de BAP testadas reduziram a formação de raízes. Franclet (1985), citado por Caldas et al. (1998), relata que o contato prolongado das culturas com elevadas concentrações de BAP, na fase de multiplicação, pode exigir até seis subcultivos em meio contendo carvão ativado para eliminar o efeito residual da citocinina e permitir um bom enraizamento.

Com relação ao comprimento da maior raiz formada, a maior média $(0,94 \mathrm{~cm})$ foi observada em brotações multiplicadas em meio não suplementado com citocinina. Contrariamente, Oliveira et al. (2007) verificaram maior comprimento de raízes em brotações de Annona glabra L. quando multiplicadas na presença das citocininas BAP, zeatina e cinetina.

Com relação ao efeito residual das diferentes fontes de citocininas, verificou-se ao final do cultivo inicial, um maior número de brotos (1,98 por explante) com a adição da citocinina BAP ao meio nutritivo. Esse valor permaneceu praticamente constante nos três subcultivos posteriores (Tabela 3), indicando a manutenção da capacidade de proliferação de brotações nos explantes caulinares de mangabeira inoculados em meio de cultura suplementado com essa citocinina.

Tabela 3 - Número médio de brotações em explantes caulinares de mangabeira inoculados em meio WPM basal e WPM suplementado com 2,0 $\mathrm{mg} \mathrm{L}^{-1}$ de 6-benzilaminopurina (BAP), cinetina (CIN) e thidiazuron (TDZ), em função do número de subcultivos.

\begin{tabular}{clccc}
\hline \multirow{2}{*}{$\begin{array}{c}\text { Fontes de } \\
\text { citocinina }\end{array}$} & Inicial & \multicolumn{3}{c}{ Subcultivos } \\
\cline { 3 - 5 } & & 1 & 2 & 3 \\
\hline Controle & $1,7 \mathrm{aA}$ & $0,8 \mathrm{bB}$ & $0,6 \mathrm{cB}$ & $0,3 \mathrm{cB}$ \\
$\mathrm{BAP}$ & $1,98 \mathrm{aA}$ & $2,1 \mathrm{aA}$ & $2,3 \mathrm{aA}$ & $2,3 \mathrm{aA}$ \\
$\mathrm{CIN}$ & $1,8 \mathrm{aA}$ & $1,7 \mathrm{aA}$ & $1,3 \mathrm{bB}$ & $1,1 \mathrm{bB}$ \\
$\mathrm{TDZ}$ & $1,7 \mathrm{aA}$ & $1,0 \mathrm{bB}$ & $1,1 \mathrm{bB}$ & $0,9 \mathrm{bB}$ \\
\hline
\end{tabular}

*Médias seguidas pela mesma letra minúscula na coluna e maiúscula na linha não diferem entre si, de acordo com o teste de Scott-Knott, a 5\% de probabilidade de erro.

Para explantes cultivados em meio de cultura sem a adição de citocininas, o maior número de brotos foi observado nos primeiros 35 dias. Nos subcultivos posteriores, uma queda no valor dessa variável resposta foi verificada. Esse mesmo padrão repetiu-se com o uso de CIN e TDZ, reduzindo a capacidade de proliferação de brotos.

Maior número de gemas foi observado em brotações mantidas em meio de cultura suplementado com BAP (Tabela 4).

Tabela 4 - Número médio de gemas em explantes caulinares de mangabeira inoculados em meio WPM basal e WPM suplementado com 2,0 $\mathrm{mg} \mathrm{L}^{-1}$ de 6-benzilaminopurina (BAP), cinetina (CIN) e thidiazuron (TDZ), em função do número de subcultivos.

\begin{tabular}{ccccc}
\hline \multirow{2}{*}{$\begin{array}{c}\text { Fonte de } \\
\text { citocinina }\end{array}$} & Inicial & \multicolumn{3}{c}{ Subcultivos } \\
\cline { 3 - 5 } & & 1 & 2 & 3 \\
\hline Controle & $5,58 \mathrm{cA}$ & $1,5 \mathrm{bB}$ & $2,4 \mathrm{bB}$ & $1,2 \mathrm{cB}$ \\
BAP & $19,22 \mathrm{aA}$ & $7,6 \mathrm{aB}$ & $9,3 \mathrm{aB}$ & $9,6 \mathrm{aB}$ \\
CIN & $10,18 \mathrm{bA}$ & $5,2 \mathrm{aB}$ & $4,1 \mathrm{bB}$ & $7,8 \mathrm{aA}$ \\
TDZ & $11,32 \mathrm{bA}$ & $2,0 \mathrm{bC}$ & $2,1 \mathrm{bC}$ & $4,6 \mathrm{bB}$ \\
\hline
\end{tabular}

*Médias seguidas pela mesma letra minúscula na coluna e maiúscula na linha não diferem entre si, de acordo com o teste de Scott-Knott, a 5\% de probabilidade de erro.

Ao final dos três subcultivos, a ausência de citocinina mostrou-se mais desfavorável à proliferação de gemas, embora todas as fontes de citocininas tenham reduzido o número de gemas ao longo dos subcultivos.

Com os sucessivos subcultivos, o BAP provocou a maior redução da capacidade de crescimento das brotações de mangabeira (Tabela 5). Entretanto, esse comportamento também foi verificado quando as plantas foram cultivadas em meio basal.

Tabela 5 - Comprimento do maior broto em explantes caulinares de mangabeira inoculados em meio WPM basal e WPM suplementado com 2,0 $\mathrm{mg} \mathrm{L}^{-1} \mathrm{de}$ 6-benzilaminopurina (BAP), cinetina (CIN) e thidiazuron (TDZ), em função do número de subcultivos.

\begin{tabular}{ccccc}
\hline \multirow{2}{*}{$\begin{array}{c}\text { Fonte de } \\
\text { citocinina }\end{array}$} & \multirow{2}{*}{ Inicial } & \multicolumn{3}{c}{ Subcultivos } \\
\cline { 3 - 5 } & & 1 & 2 & 3 \\
\hline Controle & $1,78 \mathrm{cA}$ & $0,39 \mathrm{aB}$ & $0,64 \mathrm{aB}$ & $0,37 \mathrm{cB}$ \\
BAP & $4,54 \mathrm{aA}$ & $0,95 \mathrm{aB}$ & $0,92 \mathrm{aB}$ & $1,91 \mathrm{bB}$ \\
CIN & $3,41 \mathrm{bB}$ & $1,02 \mathrm{aC}$ & $1,09 \mathrm{aC}$ & $4,52 \mathrm{aA}$ \\
TDZ & $3,12 \mathrm{bA}$ & $0,65 \mathrm{aB}$ & $0,75 \mathrm{aB}$ & $3,61 \mathrm{aA}$ \\
\hline
\end{tabular}

*Médias seguidas pela mesma letra minúscula na coluna e maiúscula na linha não diferem entre si, de acordo com o teste de Scott-Knott, a 5\% de probabilidade de erro. 
Quanto à taxa de multiplicação, o valor máximo $(9,61)$, para todos os tratamentos, ocorreu, ao final do cultivo inicial, na presença de BAP (Tabela 6).

Tabela 6 - Taxa de multiplicação em explantes caulinares de mangabeira inoculados em meio WPM basal e WPM suplementado com 2,0 mg L-1 de 6-benzilaminopurina (BAP), cinetina (CIN) e thidiazuron (TDZ), em função do número de subcultivos.

\begin{tabular}{ccccc}
\hline \multirow{2}{*}{$\begin{array}{c}\text { Fonte de } \\
\text { citocinina }\end{array}$} & Inicial & \multicolumn{3}{c}{ Subcultivos } \\
\cline { 3 - 5 } & & 1 & 2 & 3 \\
\hline Controle & $2,79 \mathrm{cA}$ & $0,75 \mathrm{bB}$ & $1,2 \mathrm{bB}$ & $0,6 \mathrm{cB}$ \\
BAP & $9,61 \mathrm{aA}$ & $3,8 \mathrm{aB}$ & $4,65 \mathrm{aB}$ & $4,8 \mathrm{aB}$ \\
$\mathrm{CIN}$ & $5,09 \mathrm{bA}$ & $2,6 \mathrm{aB}$ & $2,05 \mathrm{bB}$ & $3,9 \mathrm{aA}$ \\
TDZ & $5,66 \mathrm{bA}$ & $1,0 \mathrm{bC}$ & $1,05 \mathrm{bC}$ & $2,3 \mathrm{bB}$ \\
\hline
\end{tabular}

*Médias seguidas pela mesma letra minúscula na coluna e maiúscula na linha não diferem entre si, de acordo com o teste de Scott-Knott, a 5\% de probabilidade de erro.

Lima \& Moraes (2006), trabalhando com o cultivo de diferentes genótipos de bananeira em meio nutritivo suplementado com a citocinina BAP, observaram menores taxas de multiplicação entre o terceiro e o sexto subcultivo. Os autores sugerem que o decréscimo se deveu, provavelmente, ao acúmulo da citocinina no explante. Segundo eles, uma das maneiras para tentar maximizar a produção de brotos seria alternar concentrações altas e baixas dessa classe de reguladores.

De acordo com Santos et al. (2006), uma maior taxa de multiplicação in vitro implica na maior velocidade do processo de micropropagação e na redução da necessidade de constante estabelecimento de novas culturas.

\section{CONCLUSÕES}

O meio WPM, suplementado com 2,0 $\mathrm{mg} \mathrm{L}^{-1}$ de BAP, na fase de multiplicação, induz as melhores respostas organogênicas na cultura de segmentos caulinares de mangabeira. Brotações de mangabeira oriundas de meio de cultura WPM basal apresentam maior capacidade de enraizamento in vitro. Entre as citocininas testadas, o BAP promove a maior taxa de multiplicação de brotações de mangabeira. Os subcultivos reduzem a capacidade de multiplicação de explantes caulinares dessa espécie.

\section{REFERÊNCIAS BIBLIOGRÁFICAS}

CALDAS, L.S.; HARIDASAN, P.; FERREIRA, M.E. Meios nutritivos. In: TORRES, A.C.; CALDAS, L.S.;
BUSO, J.A. Cultura de tecidos e transformação genética de plantas. Brasília: Embrapa-SPI/Embrapa-CNPH, 1998. v.1, p.87-132.

CAMPBELL, R.J. South American fruits deserving further attention. In: JANICK, J. (Ed.). Progress in new crops. Arlington: ASHS, 1996. p.431-439.

ERIG, A.C.; SCHUCH, M.W. Multiplicação in vitro do porta-enxerto de macieira cv. Marubakaido: efeito da orientação do explante no meio de cultura. Revista Brasileira de Fruticultura, Jaboticabal, v.24, n.2, p.293295, ago. 2002.

FERREIRA, D.F. SISVAR - Sistema de análise de variância para dados balanceados. Lavras: UFLA, 1999.

GOMES, G.A.C.; PAIVA, R.;HERRERA, R.C.; PAIVA, P.D. de O. Micropropagation of Maclura tinctoria L.: an endangered woody species. Revista Árvore, Viçosa-MG, v.34, n.1, p.25-30, 2010.

GRATTAPAGLIA, D.; MACHADO, M.A. Micropropagação. In: TORRES, A.C.; CALDAS, L.S.; BUSO, J.A. Cultura de tecidos e transformação genética de plantas. Brasília: EMBRAPA-SPI/EMBRAPA-CNPH, 1998. v.1, p.183-260.

GRIBAUDO, I.; FRONDA, A. Effects of thidizuron on Grapevine axillary buds cultivated in vitro. HortScience, Alexandria, v.26, n.8, p.1083-1091, 1991.

HOWELL, S.H.; LALL, S.; CHE, P. Cytokinins and shoot development. Trends in Plant Science, Oxford, v.8, p.453-459, 2003.

HUETTEMAN, C.A.; PREECE, J.E. Thidiazuron: a potent cytokinin for wood plant tissue culture. Plant Cell, Tissue and Organ Culture, Dordrecht, v.33, n.2, p.105-119, 1993.

KIM, M.K.; SOMMER, H.E.; BONGARTIEN, B.C.; MERKLE, S.A. High-frequency induction of adventitious shoots from hypocotyl segments of Liquidambar styraciflua L. by thidiazuron". Plant Cell Reports, Berlin, v.16, n.8, p.536-540, 1997.

LIMA, E.C.; PAIVA, R.; NOGUEIRA, R.C.; SOARES, F.P.; EMRICH, E.B.; SILVA, A.A.N. Callus induction in leaf segments of Croton urucurana Baill. Ciência e Agrotecnologia, Lavras, v.32, n.1, p.17-22, jan./fev., 2008. 
LIMA, J.D.; MORAES, W. da S. Concentração de benzilaminopurina e avaliação de protocolo para multiplicação in vitro de genótipos de bananeira. Pesquisa Agropecuária Tropical, Goiânia, v.36, n.1, p.1319, 2006.

LLOYD, G.; MCCOWN, B. Use of microculture for production and improvement of Rhododendron spp. HortScience, Alexandria, v.15, n.3, p.416, June 1980.

MACHADO, M.P.; BIASI, L.A.; RITTER, M.; RIBAS, L.L.F.; KOEHLER, H.S. Multiplicação in vitro do portaenxerto de videira VR043-43 (Vitis vinifera X Vitis rotundifolia). Ciência e Agrotecnologia, Lavras, v.30, n.4, p.648-655, jul./ago. 2006.

MANTOVANI, N.C.; FRANCO, E.T.H.; VESTENA, S. Regeneração in vitro de louro-pardo (Cordia trichotoma (Vollozo) Arrábida ex Steudel). Ciência Florestal, Santa Maria, v.11, n.2, p.93-101, 2001.

MORALES, C. F. G; LOMBARDI, S.R. B.; SOARES, P.F.; FORTES, G. R. de L. Efeito do BAP e TDZ na calogênese e organogênese em internódios de macieira cv. Gala RW1. Revista Brasileira de Agrociência, Pelotas, v. 5, n.3, p. 174-177, 1999.

OLIVEIRA, L.M. de; PAIVA, R.; SANTANA, J.R.F. de; NOGUEIRA, R.C.; SOARES, F.P.; SILVA, L.C. Efeito de citocininas na senescência e abscisão foliar durante o cultivo in vitro de Annona glabra L. Revista Brasileira de Fruticultura, Cruz das Almas, v.29, n.1, p.25-30, 2007.
PERES, L.E.P. As bases fisiológicas e genéticas da regeneração de plantas in vitro: um conhecimento útil para o desenvolvimento de protocolos biotecnoógicos. Revista Biotecnologia Ciência \& Desenvolvimento, Brasília, n.25, p.44-48, 2002.

RIBEIRO, C.S.N.; SILVA, H.; SANTOS, J.W.dos; CARVALHO, J.M.F.C. Efeito do thidiazuron na micropropagação in vitro de dois genótipos de mamona via organogênese. Revista Brasileira de Engenharia Agrícola e Ambiental, Campina Grande, v. 14, n.4, p. 366371.

SANTOS, A.S. de A.; MACHADO, I.S.; LEÃO, A.L.; RAMOS, A. de. A. Concentrações de BAP e TDZ na propagação in vitro de Carauá (Ananas erectifolius L. B. Smith). Biotecnologia Ciência \& Desenvolvimento, Brasília, ano 8, n.35, p.62-65, 2005.

SANTOS, B.R.; PAIVA, R.; NOGUEIRA, R.C.; OLIVEIRA, L.M. de; SILVA, D.P.C. da; MARTINOTTO, C.; SOARES, F.P.; PAIVA, P.D. de O. Micropropagation of "pequizeiro" (Caryocar brasiliense Camb.). Revista Brasileira de Fruticultura, Cruz das Almas, v.28, n.2, p.293-296, 2006.

SOARES, F.P.; PAIVA, R.; STEIN, V.C.; NERY, F.C.; NOGUEIRA, R.C.; OLIVEIRA, L.M. de. Efeito de meios de cultura, concentrações de $\mathrm{GA}_{3}$ e $\mathrm{pH}$ sobre a germinação in vitro de mangabeira (Hancornia speciosa Gomes). Ciência e Agrotecnologia, Lavras, v.33, Edição Especial, p.1847-1852, 2009. 